\title{
Mucilage synthesis by in vitro cell culture in different species of Alyssum
}

\author{
Bahareh Afshar, Pooran GolkaR * \\ Institute of Biotechnology and Bioengineering, Isfahan University of Technology, Isfahan, Iran
}

\begin{abstract}
Mucilage is a class of polysaccharides found in some plants that have pharmaceutical effects as anti-hemorrhoids. Alyssum is one such species; its seeds produce mucilage that possesses pharmaceutical properties. The aim of this study was to optimize the conditions for callus production and mucilage synthesis in Alyssum species in a tissue culture procedure. In the study presented here, callus initiation in different genotypes of Alyssum species ( $A$. inflatum, A. lepidium, and $A$. strigosum) has been investigated for the first time. Different combinations of 2,4 Dichlorophenoxy acetic acid (2,4 D), Kinetin (Kin) and Benzyl amino purin (BAP) were used to optimize callus initiation frequency and callus growth rates (CGR) in hypocotyl explants. The highest rates of callus induction (\%) and callus growth rates (CGR) were achieved with $2.5 \mathrm{mg} \cdot \mathrm{l}^{-1} 2,4 \mathrm{D}+0.1 \mathrm{mg} \cdot \mathrm{l}^{-1} \mathrm{Kin}$ and $3 \mathrm{mg} \cdot \mathrm{l}^{-1} 2,4 \mathrm{D}$ $+0.1 \mathrm{mg} \cdot \mathrm{l}^{-1} \mathrm{Kin}$, respectively. The highest callus induction was recorded for $A$. inflatum. The mucilage content was estimated in callus cultures of different explants. The novel finding of the study is the superiority of the mucilage extracted from the callus rather than the seed, which is about ten times higher. The highest mucilage production (g/g dry weight) was obtained with Murashige and Skoog (MS) medium supplemented with $2 \mathrm{mg} \cdot \mathrm{l}^{-1}$ 2,4 $\mathrm{D}$ and $0.1 \mathrm{mg} \cdot \mathrm{l}^{-1} \mathrm{Kin}$. Among the genotypes investigated, Kerman (A. lepidium) was found to produce the most mucilage $(0.51 \mathrm{~g} / \mathrm{g}$ d.w. $)$ in its callus. The proposed method is beneficial for mucilage production from Alyssum sp. using in vitro cell culture.
\end{abstract}

Key words: callus, explant, growth, induction, medicinal plants

\section{Introduction}

Polysaccharide hydrocolloids including mucilage are abundant in nature and commonly found in many higher plants (Whistler and BeMiller, 1993; Malviya et al., 2011). Mucilage exudates provide an easy and cheap access to the stock of polysaccharides, most of which are important in food formulations, because of their ability to modify the functional properties of food systems (Kocheki et al., 2009). Mucilage is a natural polymer and is widely used in food processes as a thickener, gelling agent, or stabilizer (Koocheki et al., 2010; Malviya et al., 2011). Moreover, plant-based mucilage has wide pharmaceutical and medicinal applications (Gupta et al., 2015). Plants containing mucilage are used to treat high blood pressure, high cholesterol, diabetes, hemorrhoids and bladder problems (Malviya et al., 2011).
Alyssum is one of the six genera belonging to the Brassicaceaefamily, with species endemic to Irano-Turanian, Mediterranean, and SaharoSindian regions (Hedge, 1976). The genus comprises annual and perennial herbaceous plants that grow $10-100 \mathrm{~cm}$ tall (Al-Shehbaze and Beilstein, 2006). The species endemic to Iran include A. homolocarpum, locally called "Qudume" in Persian (or Qudume Shirazi in the local Persian), A. lepidium (or Qudume Shahri in the local Persian), A. inflatum and A. strigosum (Amin, 2005). These species are of great interest, mainly because of their phytoremediation potential via nickel hyperaccumulation (Vinterhalter and Vinterhalter, 2005; Ghasemi et al., 2009) and medicinal properties (Topcu et al., 2009; Koocheki et al., 2010).

The seeds of Qudume are distributed in different parts of Iran, especially in western, central, and sou-

\footnotetext{
* Corresponding author: Institute of Biotechnology and Bioengineering, Isfahan University of Technology, Isfahan, 8415683111, Iran; e-mail: pooran60@yahoo.com and golkar@cc.iut.ac.ir
} 
thern regions, and are used as herbs (Koocheki et al., 2010). A. lepidium has round, pale brown seeds (1.5$2.5 \mathrm{~mm}$ in diameter) that are endemic to serpentine soils of Iran (Ghaderian et al., 2007). Those of Qudume Shirazi are flat and round (1.5-2.5 $\mathrm{mm})$ in shape and reddish brown in color with dry fruits narrowly winged all around (Kocheki et al., 2009). They absorb water quickly when soaked in water and contain a large amount of mucilaginous substances (Kocheki et al., 2009).

A number of Alyssum species are commonly used in traditional herbal medicine; its seeds, in particular, are known to contain large amounts of bioactive substances (Topcu et al., 2009). For centuries, Qudume seeds have been prescribed by herbalists for their mucilage content, especially as remedies, such as demulcents for dry coughs, asthma, lung infections and kidney stones (Amin, 2005; Kocheki et al., 2009).

While many parts of Iran, especially the central regions, offer favorable agro-climatic conditions for the production of Alyssum, the availability of Alyssum sp. is becoming scarce due to its narrow genetic diversity. It is anticipated that some species of Alyssum, such as $A$. inflatum and $A$. strigum, will face extinction and severe genetic loss if necessary cultivation steps are not taken in time.

Plant cell culture has emerged as a potential source of genetic preservation, while it is also a method of interest for the production of secondary metabolites which are used as pharmaceuticals, agrochemicals, and food additives (Raoa and Ravishankar, 2002; Namedo, 2007; Sree et al., 2010). Moreover, research into various plant cells, tissues, and organ cultures has enabled an evaluation of the capability of these cultures to synthesize secondary metabolites (Bourgaud et al., 2001; Rajikumar et al., 2010). Plant cell cultures are currently used in medicinal industries as a source of high value secondary metabolites (Raoa and Ravishankar, 2002).

Indeed, these cultures serve as alternatives for obtaining products that are otherwise difficult to obtain by conventional methods or whose production is not economically viable (Rajikumar et al., 2010). It has been reported that callus cultures are relatively rich in mucilage, commonly making up between $8-10 \%$ of their weights (Kokate and Radwan, 1978). Even though Qudume seeds produce a desirable amount of mucilaginous substances when wetted under optimized protocols (Koocheki et al., 2009), no study has been conducted on its extraction from callus cultures. in vitro cell cultures provide efficient means for the production of mucilage at the cellular level (Gupta et al., 2015). Moreover, the system of cell suspension cultures is a very promising method that can be exploited for the commercial production of mucilage. Mucilage synthesis has been reportedly accomplished by callus cultures of Plantago lanceolata (Mirmasumi et al., 2001), Plantago major (Mirmasumi et al., 2001), and Plantago ovata (Gupta et al., 2015). A successful mucilage synthesis by in vitro culture, however, requires callus production to be initially optimized in Alyssum sp. Our literature review showed no published reports on callus induction of Iranian and exotic genotypes of A. lepidium or A. Strigosum. Paunescu (2008) reported that different combinations of auxins $(2,4 \mathrm{D}$, IAA, and NAA) and cytokinins (BAP and Kin) led to no callus induction on Alyssum borzaenum, but rather only to direct shoot regeneration. Ghasemi and Samie (2013) investigated callus induction in $A$. inflatum by applying a combination of $1.5 \mathrm{mg} \cdot 1^{-1} 2,4 \mathrm{D}$ and $0.1 \mathrm{mg} \cdot 1^{-1} \mathrm{Kin}$.

Considering the wide-ranging applications of mucilage and the ecological importance of the Alyssum plant species as a new source of mucilage, the present study was designed and implemented to investigate the composition of its constituent monosaccharides. As a second objective, callus production and mucilage synthesis of the three species of Alyssum (lepidium, strigosum, and inflatum) were optimized for the first time. The developed protocol may not only serve as a valuable alternative to the ex-situ conservation of this endangered species with its very narrow genetic diversity, but may also be employed to extract and preserve bioactive substances from these species of Alyssum.

\section{Materials and methods}

\section{Explant preparation and callus induction}

This experiment was conducted at the Tissue Culture Laboratory of the Institute of Biotechnology and Bioengineering at Isfahan University of Technology in 2015 using a completely randomized factorial split plot design with five replications. The combinations of plant growth regulators and genotypes were considered as the main plots, while time (in months) formed the subplots. The seeds of five accessions of Iranian Alyssum genotypes were collected from different geographical regions of Iran; these included $A$. lepidium (collected from Isfa- 
han, Jiroft, and Yazd), A. inflatum (collected from Kerman), and A. strigosum (collected from Qom). The seeds of Alyssum sp. were optimized using different treatments to enhance their germination percentage. For this purpose, they were initially sterilized in a $5 \% \mathrm{w} / \mathrm{v}$ sodium hypochlorite solution for $3 \mathrm{~min}$ before being washed three times with sterile distilled water. The sterilized seeds were aseptically germinated on agar-solidified Murashige and Skoog (MS) (1962) basal medium at a temperature of $24 \pm 1^{\circ} \mathrm{C}$ and a relative humidity of $50 \pm 5 \%$ in $16-8 \mathrm{~h}$ (light-dark) cycles using a lab germinator.

Table 1. Different types and concentrations of plant growth regulators used for callus induction from hypocotyl explants of Alyssum sp. on MS medium

\begin{tabular}{c|c}
\hline Number & PGRs $\left(\mathrm{mg} \cdot 1^{-1}\right)$ \\
\hline 1 & $2,4 \mathrm{D}(1.5)+\operatorname{Kin}(0.5)$ \\
\hline 2 & $2,4 \mathrm{D}(2)+\operatorname{Kin}(0.5)$ \\
\hline 3 & $2,4 \mathrm{D}(2.5)+\operatorname{Kin}(0.5)$ \\
\hline 4 & $2,4 \mathrm{D}(3)+\operatorname{Kin}(0.5)$ \\
\hline 5 & $2,4 \mathrm{D}(1.5)+\operatorname{Kin}(0.1)$ \\
\hline 6 & $2,4 \mathrm{D}(1.5)+\operatorname{BAP}(0.1)$ \\
\hline 7 & $2,4 \mathrm{D}(2)+\operatorname{BAP}(0.5)$ \\
\hline
\end{tabular}

Hypocotyl segments $(2-3 \mathrm{~mm})$ were excised from 14day-old seedlings of all the genotypes investigated to be used as explants for callus induction. The hypocotyl pieces were cultured on the MS medium (Duchefa) supplemented with different concentrations of 2,4D, Kinetin (Sigma), NAA (Naphthalene acetic acid) (Sigma), and BAP (Benzyl amino purine) (Sigma) in $30 \mathrm{gl}^{-1}$ sucrose, and $0.1 \mathrm{mgl}^{-1}$ myoinositol for callus initiation (Table 1). The $\mathrm{pH}$ of the media was adjusted to 5.8 and solidified with $0.8(\%)(w / v)$ agar (Sigma) before autoclaving for $20 \mathrm{~min}$ at a pressure of $1.06 \mathrm{~kg} / \mathrm{cm}^{2}$. Petri dishes were incubated in the dark at $25 \pm 1^{\circ} \mathrm{C}$ (six explants cultured in each dish). For callus induction, the hypocotyl cultures were maintained in a dark incubator (Binder Model, Bd-115) at $24 \pm 1^{\circ} \mathrm{C}$ for 1 month before they were transferred to fluorescent light over a $16 \mathrm{~h}$ photoperiod with a photon flux density of $40 \mu \mathrm{mol} / \mathrm{m}^{2}$ at $25 \pm 1^{\circ} \mathrm{C}$. Sub-culturing of the callused explants was performed twice a month.

The percentage of callogenesis was calculated using the following equation: [ $(n / N) \times 100]$, in which $n$ is the total number of callused explants and $N$ represents the total number of cultured explants (Wakhlu and Barna, 1989).

The callus growth rate (CGR) was calculated based on the means of callus growth rates (mm/day) at 30,60 , 90 , and 120 days after callus induction using the following equation (Compton, 1994):

$$
\begin{gathered}
c g r=\frac{c g r_{1}+c g r_{2}+c g r_{3}+c g r_{4}}{4} \\
c g r_{1}=\frac{d_{30}}{30}, \quad c g r_{2}=\frac{d_{60}}{30}, \quad c g r_{3}=\frac{d_{90}}{30}, \quad c g r_{4}=\frac{d_{120}}{30}
\end{gathered}
$$

Callus diameter $\left(d_{i}\right)$ was calculated as the square root of the product of callus length and callus width. It should be noted that callus diameter for each of the experimental ages (i.e., $d_{30}, d_{60}, d_{90}$, and $d_{120}$ ) was calculated as the difference between callus diameter at a given age and that at the preceding age.

\section{Mucilage extraction}

The method described in Sharma and Koul (1986) was used, with minor modifications, to extract mucilage from Alyssum sp. calluses. In this procedure, ten milliliters of $0.1 \mathrm{NHCl}$ was heated to boiling point in a $100-\mathrm{ml}$ corning flask. After removing the flask from the flame, $1 \mathrm{~g}$ of fresh callus was added to it and heating was resumed. After $5 \mathrm{~min}$, the solution was filtered through a piece of clean muslin cloth while still hot. In order to separate residual traces of mucilage, the mucilage was washed twice in $5 \mathrm{ml}$ of hot water and the solution thus obtained was filtered each time. The combined filtrate solution containing the dissolved mucilage was mixed with $60 \mathrm{ml}$ of $95 \%$ ethyl alcohol, stirred, and allowed to stand for $5 \mathrm{~h}$ in a refrigerator at $4{ }^{\circ} \mathrm{C}$. Finally, the supernatant was decanted and the beaker containing the precipitate was dried in an oven maintained at $50^{\circ} \mathrm{C}$ for $12 \mathrm{~h}$ to calculate the mucilage content in dry weight.

\section{Statistical analysis}

The data were subjected to an analysis of variance using PROC ANOVA in the SAS statistical package (Ver. 9.1). Mean comparisons were conducted using the least significant difference $\left(\mathrm{LSD}_{0.05}\right)$ method.

\section{Results and discussion}

Results of the preliminary experiment using different explants including hypocotyls, cotyledons, and 
Table 2. Analysis of variance (ANOVA) for genotype, hormone, incubation period and their interaction effects for callus induction and callus growth rate in Alyssum sp.

\begin{tabular}{l|c|c|c}
\hline \multirow{2}{*}{ Source of variation } & \multirow{2}{*}{$\mathrm{df}^{*}$} & \multicolumn{2}{c}{ Mean squares } \\
\cline { 3 - 4 } & & callus induction & callus growth rate \\
\hline Genotype & 4 & $0.055^{* *}$ & $0.083^{* *}$ \\
\hline Hormone & 4 & $0.0152^{* *}$ & $0.0387^{* *}$ \\
\hline Genotype $\times$ hormone & 16 & 0.0056 & 0.0038 \\
\hline Error $(\mathrm{a})$ & 100 & 0.0034 & 0.0083 \\
\hline Incubation period & 3 & $24.88^{* *}$ & $0.306^{* *}$ \\
\hline Genotype $\times$ incubation period & 12 & $0.0314^{* *}$ & $0.082^{* *}$ \\
\hline Hormone $\times$ incubation period & 12 & $0.015^{* *}$ & $0.033^{* *}$ \\
\hline Hormone $\times$ incubation period $\times$ genotype & 48 & 0.0036 & 0.011 \\
\hline Error $(b)$ & 300 & 0.0028 & 0.009 \\
\hline
\end{tabular}

*, ** are significant at $P<0.05$ and $P<0.01$, respectively; ${ }^{*}$ - degree of freedom

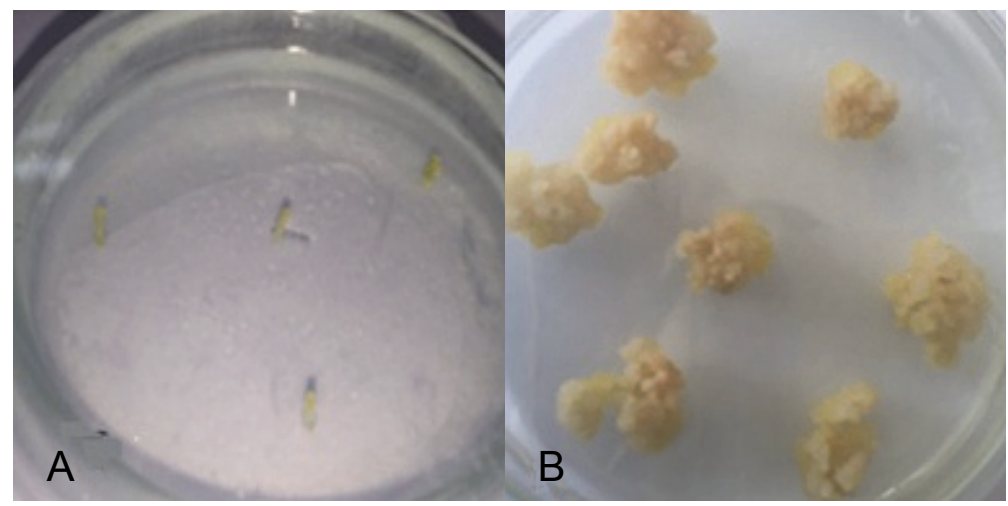

Fig. 1. The callus induction from A. lepidium hypocotyls (A), and callus growth explants (B) after four months of induction, on Murashige and Skoog (MS) medium with $2.5 \mathrm{mg} \cdot 1^{-1} 2,4 \mathrm{D}$ and $0.1 \mathrm{mg} \cdot 1^{-1} \mathrm{Kin}$

seeds cultured on the MS medium showed that only hypocotyl explants led to callus induction. They were, therefore, selected for further experiments. The analysis of variance showed that genotypes, hormones, incubation period, genotype $\times$ incubation period, and hormone $\times$ incubation period showed significant differences with respect to callus induction (\%) and callus growth rate (mm day) at $P<0.05$ (Table 2).

\section{Hormone assay}

For callus induction, hypocotyls are normally cultured on a medium containing growth-regulating substances (Fig. 1). The in vitro hypocotyl explants of $A l y$ sum sp. cultured in the media became swollen after one month of culture. This happened before signs of callus formation were observed, although with a low frequency of callogenesis at different concentrations of 2,4 D + Kin. Callus initiation was observed after the hypocotyls swelled at their cut surfaces. It has been reported that wounding induces the release of plant hormones that elicit cell dedifferentiation and callus induction (Kahl, 1983). Application of NAA and BAP showed no obvious effects on callus initiation. Explants were observed to swell slowly without any modification of epidermal cells in the treatments containing combinations of 2,4D + BAP and $\mathrm{NAA}+$ Kin. These cultures on fresh media did not lead to any morphological events.

These findings demonstrate the importance of the components of different plant growth regulators and explants for callus initiation and growth. It was found that the combination of the 2,4D + Kin had the most prominent effect on hypocotyl dedifferentiation and cal- 


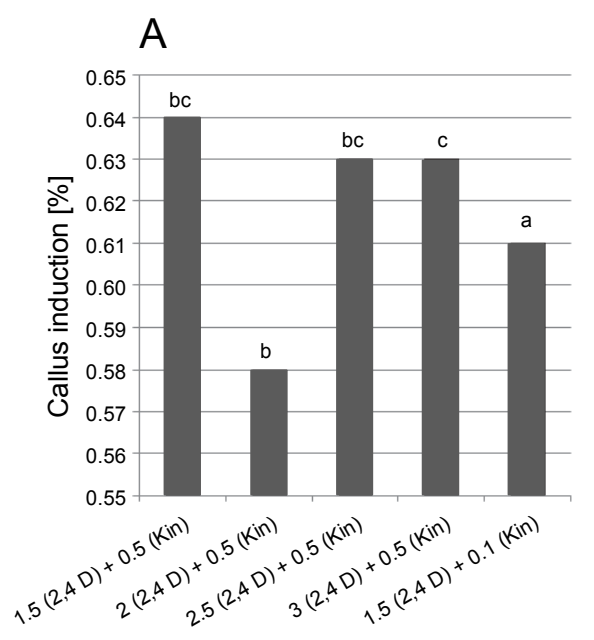

Plant growth regulators $\left[\mathrm{mg} \cdot \mathrm{I}^{-1}\right]$

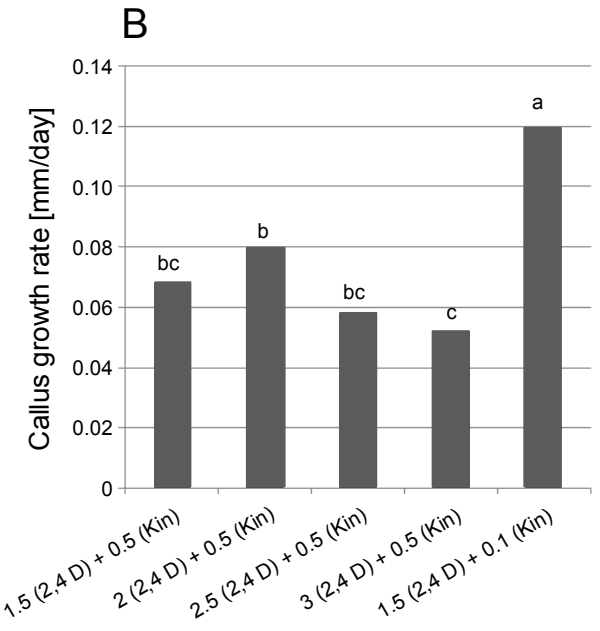

Plant growth regulators $\left[\mathrm{mg} \cdot \mathrm{I}^{-1}\right]$

Fig. 2. The effect of different plant growth regulators on A) callus induction (\%) and B) callus growth rate in Alyssum sp.

A

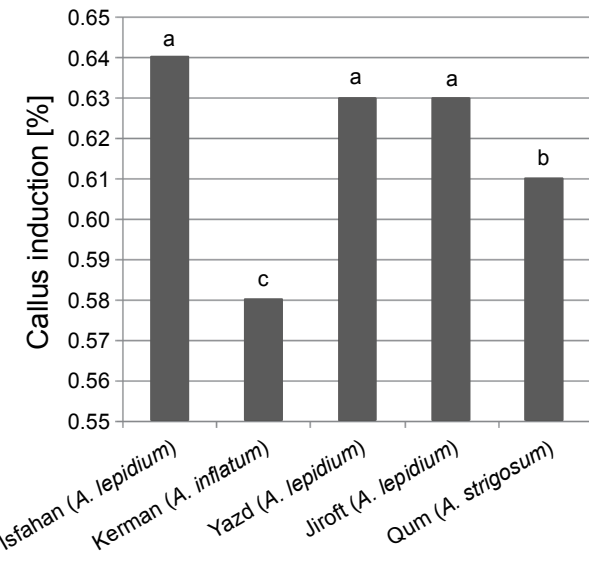

Genotypes

\section{B}

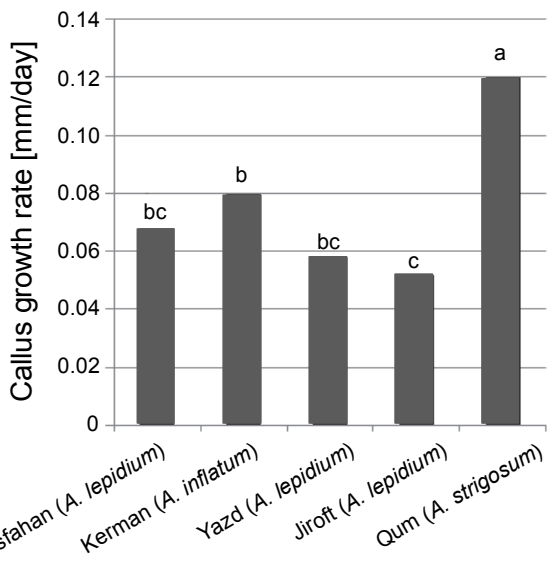

Genotypes

Fig. 3. The response of different Alyssum species to A) callus induction (\%) and $\mathrm{B}$ ) callus growth rate in in vitro hypocotyl cultures

lus induction in Alyssum species, which is in agreement with the findings of Ghasemi and Samie (2013). No callus induction was observed on the MS medium containing 2,4 D, NAA + Kin and 2,4 D + BAP, but the percentage of callogenesis increased from $58 \%$ in medium containing $2 \mathrm{mg} \cdot 1^{-1} 2,4 \mathrm{D}+0.5 \mathrm{mg} \cdot 1^{-1}$ Kin to $64.4 \%$ in medium containing $1.5 \mathrm{mg} \cdot \mathrm{l}^{-1} 2,4 \mathrm{D}+0.5 \mathrm{mg} \cdot \mathrm{l}^{-1} \mathrm{Kin}$ (Fig. 2A). Our findings concerning the nature of the calluses confirm those by Paunescu (2008), who reported that the combination of $1 \mathrm{mg} \cdot 1^{-1}$ of $2,4 \mathrm{D}$ and $0.1 \mathrm{mg} \cdot 1^{-1}$ of Kin had the greatest effect on callus induction in A. borzaenum, producing embryogenic callus of globular shape. Investigation into the effects of different combina- tions of hormones on CGR revealed that $1.5 \mathrm{mg} \cdot \mathrm{l}^{-1} 2,4 \mathrm{D}$ and $0.1 \mathrm{mg} \cdot 1^{-1} \mathrm{Kin}$ led to the highest callus growth rate (0.12 mm/day), but $3 \mathrm{mg} \cdot 1^{-1} 2,4 \mathrm{D}+0.5 \mathrm{mg} \cdot 1^{-1} \mathrm{Kin}$ led to the lowest CGR $(0.052 \mathrm{~mm} /$ day $)$ - Figure 2B.

\section{Genotypic assay}

The evaluated genotypes showed significant differences in their callus initiation and callus growth rates. The calluses of $A$. inflatum were pale green to yellow and friable, i.e. easily fell apart, but those of other species were dark to pale yellow with a compact structure.

The mean percentage values for callus induction (\%) ranged from $64 \%$ in $A$. lepidium (Isfahan) to $58 \%$ in Ker- 


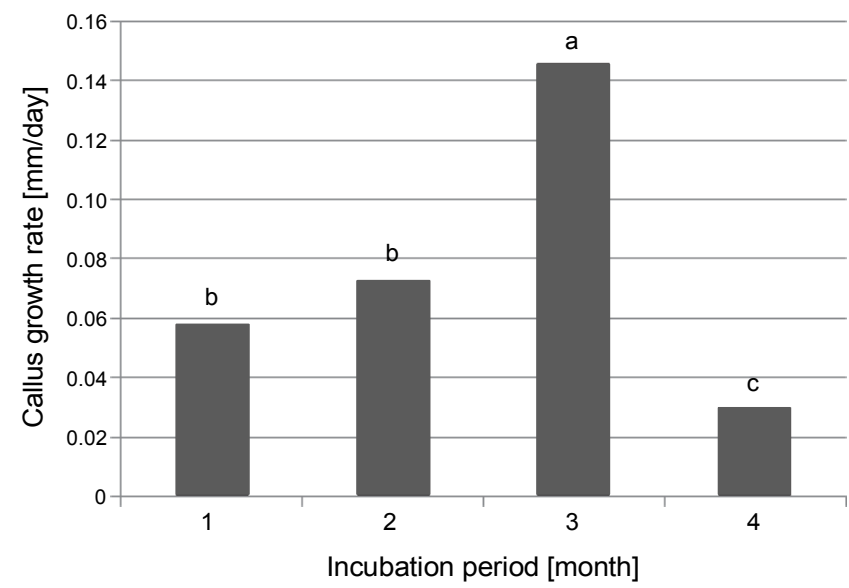

Fig. 4. The callus growth rate (mm/day) of Alyssum sp. at four sequential months after callus induction

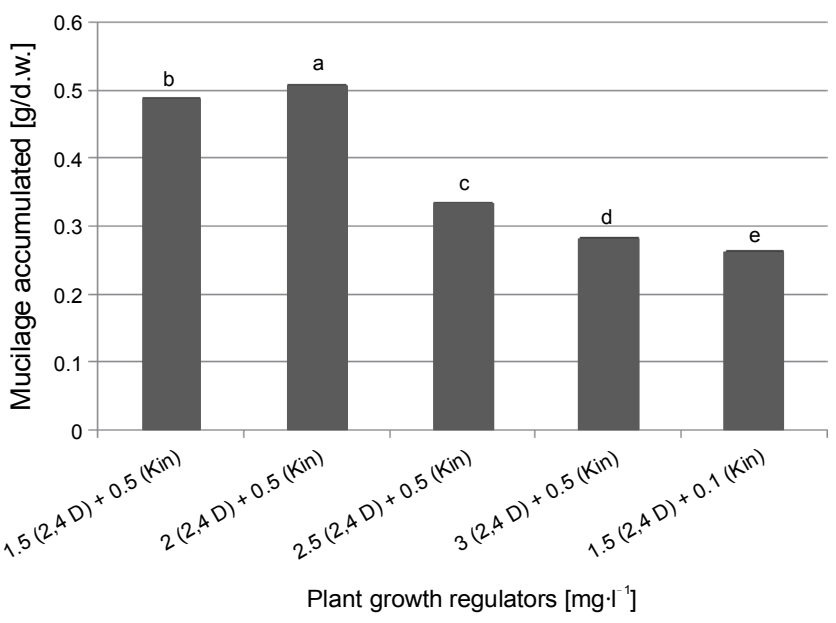

Fig. 5. The effect of different plant growth regulators $\left(\mathrm{mg} \cdot \mathrm{l}^{-1}\right)$ on mucilage accumulation on callus cultures of Alyssum sp.

man accession $A$. inflatum - (Fig. 3A). The comparison of means in the evaluated genotypes showed that the highest $(0.12 \mathrm{~mm} /$ day $)$ and the lowest $(0.052 \mathrm{~mm} /$ day $)$ CGR were observed in Qom (A. strigosum) and Kerman accessions (A. inflatum), respectively (Fig. 3B).

The comparison of callus growth rates at four sequential times - 30, 60, 90, and 120 days after callus initiation - with the plant growth regulators examined showed that the highest $(0.146 \mathrm{~mm} /$ day $)$ and the lowest $(0.03 \mathrm{~mm} /$ day $)$ CGR were recorded in the third and fourth months, respectively (Fig. 4).

The comparison of callus induction (\%) in the explants at different times showed that callus induction increased slowly from the first (13\%) to the fourth months (100\%). The comparison of callus induction in Alyssum sp. during these periods demonstrated that the rate

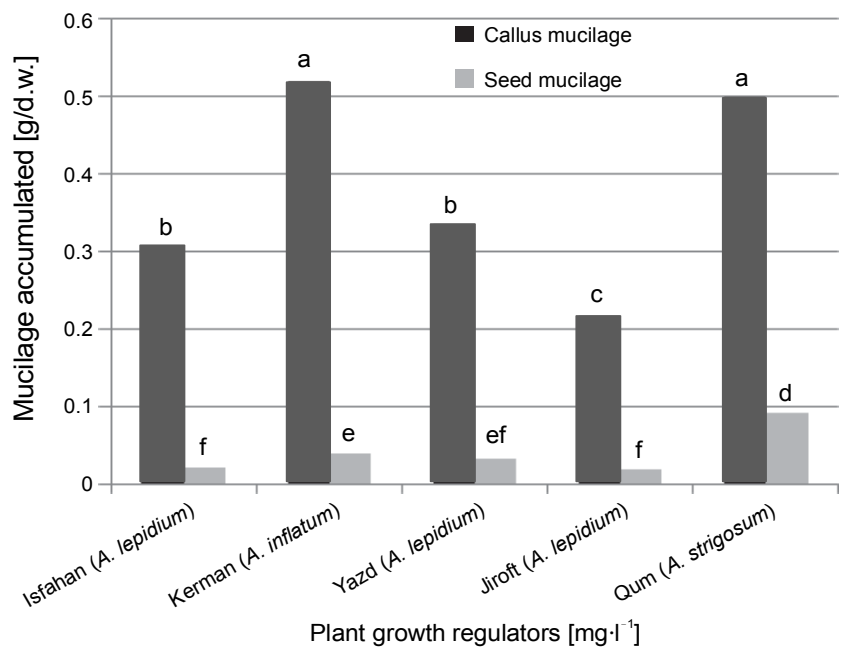

Fig. 6. The accumulated mucilage (g/g d.w.) of different genotypes of Alyssum by hypocotyls in in vitro culture

of callus induction in these species was slow. Moreover, our results showed that light had a dramatic effect on the differentiation of Alyssum explants.

The analysis of variance of callus and seed mucilage contents revealed significant differences among the genotypes and hormone treatments (data not shown). The highest mucilage content in dry weight $(0.501 \mathrm{~g} / \mathrm{g}$ d.w.) was achieved in the in vitro cell culture at a hormone combination of $2 \mathrm{mg} \cdot 1^{-1} 2,4 \mathrm{D}+0.1 \mathrm{Kin}$, while the lowest $(0.265 \mathrm{~g} / \mathrm{g}$ d.w. $)$ was obtained with $1.5 \mathrm{mg} \cdot \mathrm{l}^{-1}$ $2,4 \mathrm{D}+0.1 \mathrm{mg} \cdot 1^{-1}$ Kin (Fig. 5).

The highest $(0.520 \mathrm{~g} / \mathrm{g}$ d.w. $)$ and the lowest $(0.218 \mathrm{~g} / \mathrm{g}$ d.w. $)$ callus mucilage quantities extracted were recorded for Kerman (A. inflatum) and Jiroft (A. lepidium), respectively (Fig. 6 ). The seed mucilage content varied from 0.021 (g/g d.w.) in Jiroft (A. lepidium ) to 0.093 (g/g d.w.) in Qum (A. strigosum). Clearly, Jiroft (A. lepidium) recorded the least mucilage content under both extraction methods. This indicates the superiority of the Kerman A. inflatum var for traditional mucilage production. The best finding of the present study was that the amount of mucilage extracted from callus culture was approximately 10-times higher than the mucilage extracted from seeds. This is similar to reports on callus mucilage extracted in $P$. lanceolata (Mimasoomi et al., 2001) and P. ovata (Gupta et al., 2015).

Similar results have been reported for the increased extraction of solasodine in Solanum nigrum (Yogananth et al., 2009), taxol in Taxus baccata (Khosroushahi et al., 2005), artemisinin in artemisia annua (Pu et al., 
2009), nitidine in Toddalia asiatica (Rajkumar et al., 2010), stevioside in stevia rebaudiana (Janarthanam et al., 2010), ajmalicine and indole alkaloide in Catharanthus roseus (Zhao et al., 2001; Namdeo, 2002), jaceosidin and syringin in Saussurea medusa ( $\mathrm{Yu}$ et al., 2006), and artemisinin in Artemisia annua (Pu et al., 2009) from in vitro cell cultures, all of which were much higher than the extracts obtained from field grown plants. The chemical structures of secondary metabolites are usually complex and their production is costly, but plant cell tissue cultures could help overcome these limitations.

\section{Conclusions}

In this paper, we have described a newly developed procedure for callus initiation of $A$. lepidium, $A$. strigosum, and $A$. inflatum. This report provides a new and efficient method for the production of mucilage by a cell culture of Alyssum species. We managed to stimulate the formation and accumulation of mucilage by hypocotyl culture of Alyssum species. The significant features of this study include the production of mucilage from seeds of $A$. inflatum and $A$. strigosum as well as a significant increase in mucilage production within a relatively short time span in callus cultures of Alyssum sp. For future research, attempts should be made to produce cell suspension cultures from callus collections and to investigate the production of mucilage in liquid media to which both biotic and abiotic elicitors are added for enhanced synthesis. These results suggest that enhancement of mucilage by elicitation and precursor feeding of a cell suspension culture of Alyssum in a bioreactor can be targeted in the future.

\section{Acknowledgements}

The authors would like to thank Dr. Hossein Zeinali at Agriculture and Natural Science Research Center of Isfahan in Iran for his gratefully comments about the initiation of this research work.

\section{References}

AL-Shehbaze I., Beilstein M.A. (2006) Systematic and phylogeny of the Brassicaceae (Cruciferae): an overwiew. Plant Syst. Evol. 56: 89-120.

Amin G.H. (2002) Medicinal plants of Iran. Tehran University Publication, Tehran, Iran, (1st ${ }^{\text {ed }}$.) p. 106 (in Persian).

Bourgaud F., Gravot A., Miles S. (2001) Production of plant secondary metabolites: a historical perspective. Plant Sci. 161: 839-851.
Compton M.E. (1994) Statistical methods suitable for the analysis of plant tissue culture data. Plant Cell Tiss. Org. Cult. 37: 217-242.

Ghaderian S.M., Mohtadi A., Rahiminejad R., et al. (2007) Hyper accumulation of nickel by two Alyssum species from the serpentine soils of Iran. Plant Soil 293: 91-97.

Ghasemi R., Ghaderian S.M., Kramer U. (2009) Accumulation of nickel in trichomes of a nickel hyperaccumulator plant, Alyssum inflatum. Northeastern Naturalist 16: 91-92.

Ghasemi R., Samie R.M. (2013) Change of Ni tolerance parameters by light in Calli of a Ni hyperaccumulator plant Alyssum inflatum. J. Cell Tiss. 4(1):13-24 (in Persian).

Gupta M., Kour B., Kaul S., Dhar M.K. (2015) Mucilage synthesis in callus cultures o1 Plantago ovata Forsk. Natl. Acad. Sci. Lett. 38: 103-106.

Janarthanam B., Gopalakrishnan M., SekarT. (2010) Secondary metabolite production in callus cultures of Stevia rebaudiana Bertoni. Bangladesh J. Sci. Ind. Res. 45: 243-248.

Kahl G. (1983) Wound repair and tumor induction in higher plants. [in:] The new frontiers in plants biochemistry. Eds. Akazawa T., Imasei H. Japan Sci. Soc. Press, Tokyo: 193-216.

Khosroushahi A., Valizadeh M., Ghasempour M., et al. (2005) Improved taxol production by combination of inducing factors in suspension cell culture of Taxus baccata. Cell Biol. Int. 30: 262-269.

Kocheki A., Mortazavi SA., Shahidi F., et al. (2009) Rheological properties of mucilage extracted from Alyssum homolocarpum seed as a new source of tickening agent. J. Food Eng. 91(3): 490-496.

Kokate. C.K., Radwan S.S. (1978) Mucilage in callus culture of higher plants. Phytochemistry 18: 662-663.

Koocheki A., Mortazavi S.A., Shahidi F., et al. (2010) Optimization of mucilage extraction from Qodume shirazi seed (Alyssum homolocarpum) using response surface methodology. J. Food Process Eng. 33: 861-882.

Ling A.N.K., Tan K.P., Hussein S. (2013) Comparative effects of plant growth regulators on leaf and stem explants of Labisia pumila var. alata. J. Zhejiang. Univ. Sci. B: Biomed. Biotech. 14(7): 621-631.

Malviya R., Srivastava P., Kulkarni G.T. (2011) Applications of mucilages in drug delivery. Adv. Biol. Res. 5: 1-7.

Mirmasumi M., Ebrahimzadeh H., Tabatabaei M. (2001) Mucilage production in tissue culture of Plantago lanceolata. J. Agric. Sci. Tech. 3: 155-160.

Murashige T., Skoog F. (1962) A revised medium for rapid growth and bio assays with tobacco tissue cultures. Physiol. Plant 15: 473-497.

Namdeo A. (2002) Influence of fungal elicitors on production of ajmalicine by cell cultures of Catharanthus roseus. Biotechnol. Prog. 18: 159-162.

Namdeo A. (2007) Plant cell elicitation for production of secondary metabolites: A review. Pharmacognosy Rev. 1: 320-345.

Paunescu A. (2008) Histological investigation of the secondary somatic embryogenesis of Alyssum borzaenum (Brassicaceae). Phytol. Balcan. 14(1): 111-117. 
Pu G.B., Dong-Ming M., Chen J.L., et al. (2009) Salicylic acid activates artemisinin biosynthesis in Artemisia annua $L$. Plant Cell Rep. 28: 1127-1135.

Raoa S.R., Ravishankar G.A. (2002) Plant cell cultures: Chemical factories of secondary metabolites. Biotech. Adv. 20: 101-153.

Sharma P.K., Koul A.K. (1986) Mucilage in seeds of Plantago ovate and its wild allies. J. Ethnopharmacol. 17: 289-295.

Sharma R. (2004) Agro-Techniques o1 medicinaı plants. Daya Publishing House.

Sree N.V., Udayasri P., Aswani Y.V.V.K., et al. (2010) Advancements in the production of secondary metabolites. J. Nat. Prod. 3: 112-123.

Topçu G., Tümen G., Kiliç T., et al. (2009) Bioactive Turkish Plant Extracts and Their Constituents. [in:] Innovations in Chemical Biology. Ed. Sener B. Springer, Netherlands: 61-81.
Vinterhalter B., Vinterhalter D. (2005) Nickel hyperaccumulation in shoot cultures of Alyssum markgrafii. Biol. Plant. 49(1): 121-124.

Whistler R.L., BeMiller J.N. (1993) Industrial gums: Polysaccharides and their derivatives. $3^{\text {rd }}$ Edition. Academic Press, London.

Yogananth N., Bhakiyaraj R., Chanthuru A., et al. (2009) Comparative analysis of solasodine from in vitro and in vivo cultures of Solanum nigrum linn. Kathmandu Univ. J. Sci. Eng. Technol. 5(1): 99-103.

Yu Z., Fu C.X., Han Y.C., et al. (2006) Salicylic acid enhances jaceosidin and syringin production in cell cultures of Saussurea medusa. Biotechnol. Lett. 8: 1027-1031.

Zhao J., Zhu. W., Hu Q. (2001) Selection of fungal elicitors to increase indole alkaloid accumulation in Catharanthus roseus suspension cell culture. Enzyme Microbiol. Technol. 28: 666-672. 